\title{
Hepatoprotective effect of curcumin and alpha-tocopherol against cisplatin-induced oxidative stress
}

\author{
Sarawoot Palipoch ${ }^{1 *}$, Chuchard Punsawad ${ }^{1}$, Phanit Koomhin ${ }^{1}$ and Prasit Suwannalert ${ }^{2}$
}

\begin{abstract}
Background: cis-Diammineplatinum (II) dichloride (cisplatin) is the important anti-cancer agent useful in treatment of various cancers. Unfortunately, it can produce unwanted side effects in various tissues, including the liver. The present study investigated the possible protective role of curcumin and a-tocopherol against oxidative stress-induced hepatotoxicity in rats upon cisplatin treatment.

Methods: Male Wistar rats were divided into five groups $(n=5)$. Saline and Cis groups, rats were intraperitoneal (i.p.) injected with normal saline and cisplatin [20 mg/kg body weight (b.w.)], respectively. Cis + a-tocopherol group, Cis + Cur group and Cis + a-tocopherol + Cur group, rats were pre-treated with a single dose of a-tocopherol (250 mg/kg b.w.), curcumin (200 mg/kg b.w.) and combined a-tocopherol with curcumin, respectively, for $24 \mathrm{~h}$ prior the administration of cisplatin. After $72 \mathrm{~h}$ of first injection, specimens were collected. Liver enzyme, lipid peroxidation biomarker, liver histopathology and gene expression of liver nicotinamide adenine dinucleotide phosphate (NADPH) oxidase were investigated.

Results: Cisplatin revealed a significant increase of hepatic malondialdehyde (MDA) levels and a significant reduction of hepatic superoxide dismutase (SOD) and catalase activities compared to the saline group. It elicited a marked increase of the serum alanine aminotransferase (ALT) and aspartate aminotransferase (AST) levels and demonstrated the liver pathologies including liver congestion, disorganization of hepatic cords and ground glass appearance of hepatocytes. It also demonstrated a significant increase of NADPH oxidase gene expression compared to saline group. Pre-treatment with combined curcumin and a-tocopherol improved the liver enzymes, lipid peroxidation biomarker, liver histopathology and gene expression of liver NADPH oxidase in cisplatin-treated rats.
\end{abstract}

Conclusions: The findings indicate that pre-treatment with combined curcumin and a-tocopherol can protect cisplatininduced hepatotoxicity including the biochemical, histological and molecular aspects. The down-regulations of NADPH oxidase gene expression may be involved in abrogating oxidative stress via reduction of reactive oxygen species (ROS) production.

Keywords: Cisplatin, Oxidative stress, Curcumin, a-Tocopherol, Hepatotoxicity

\section{Background}

cis-Diammineplatinum (II) dichloride (cisplatin) is the important chemotherapeutic agent useful in the treatment of various cancers [1]. Unfortunately, it can produce side effects in various tissues, including the liver. Although the mechanism of cisplatin-induced adverse effect is still unclear, however several evidences have shown that its hepatotoxicity is believed via reactive oxygen species (ROS) generation-mediated oxidative stress

\footnotetext{
* Correspondence: spalipoch@hotmail.com

'School of Medicine, Walailak University, Nakhon Si Thammarat 80161, Thailand Full list of author information is available at the end of the article
}

dependent mechanism [2-4]. Oxidative stress is caused by an imbalance between oxidant and antioxidant. It has been implicated in the pathogenesis of various diseases $[5,6]$. ROS are the highly reactive molecules which are mainly composed of superoxide radical $\left(\mathrm{O}_{2}{ }^{-}\right)$, hydroxyl radical $\left({ }^{\circ} \mathrm{OH}\right)$ and hydrogen peroxide $\left(\mathrm{H}_{2} \mathrm{O}_{2}\right)$. It can damage biological molecules including lipid, protein and DNA and eventually cause disruption of the cellular structural integrity and capacity [7]. NADPH oxidase is a membrane-bound enzyme which has the ability to generate high levels of $\mathrm{O}_{2}{ }^{-}$in response to stimulus [8]. Previous studies revealed that the suppression of NADPH 
oxidase is able to prevent oxidative stress-induced pathology $[9,10]$.

To prevent oxidative stress, there are several molecules that play a role to scavenge ROS called antioxidant which derived from both exogenous and endogenous sources. Superoxide dismutase (SOD) is one of the most powerful endogenous enzymatic antioxidants which has the ability to convert $\mathrm{O}_{2}{ }^{--}$into $\mathrm{H}_{2} \mathrm{O}_{2}$. The absence of SOD demonstrates the elevated oxidative damage causing various pathologies in vivo $[11,12]$. Catalase is also the important endogenous enzymatic antioxidant responsible for protection of the cell from oxidative damage induced by ROS via converting $\mathrm{H}_{2} \mathrm{O}_{2}$ into water and oxygen. Catalase deficiency leads to oxidative stress by increasing lipid peroxidation as demonstrated in mice [13].

Medicinal plants are good sources of exogenous antioxidants which might be considered as the new alternative approach to ameliorate pathological alterations in oxidative stress-related pathology. Curcumin is derived from the rhizomes of Curcuma longa which has been demonstrated to possess antioxidant activity in vivo [14]. It has been demonstrated to prevent several pathologies related to oxidative damage such as the inorganic arsenic-induced hepatotoxicity [15]. We hypothesized that treatment with combined curcumin and $\alpha$-tocopherol may have higher antioxidant ability than treatment with curcumin or $\alpha$ tocopherol alone. Additionally, $\alpha$-tocopherol is one of the most biologically active forms of vitamin E. The study aimed at gaining insight into the understanding of the biochemical, histological and molecular effects of curcumin and/or $\alpha$-tocopherol to protect against cisplatin-induced oxidative stress in rat liver.

\section{Methods}

\section{Chemicals}

cis-Diammineplatinum (II) dichloride (product number: 479306, purity $\geq 99.9 \%$ ), curcumin from Curcuma longa (product number: c1386, purity $\geq 65 \%$ ), $\alpha$-tocopherol (product number: 258024, purity $\geq 95.5 \%$ ), Bradford assay kits and $10 \%$ neutral buffered formalin solution were purchased from Sigma-Aldrich Chemical Company (St. Louis, MO, USA). Thiobarbituric Acid Reactive Substances (TBARS), SOD and catalase assay kits were obtained from Cell Biolabs, Inc (San Diego, CA, USA). RNeasy mini kit, Omniscript RT kit and HotStar Taq DNA polymerase were obtained from Qiagen (Hilden, Germany). All other chemicals were of analytical grade.

\section{Animals}

Twenty-five male Wistar rats (Rattus norvegicus), ranking from 180-200 g, were obtained from the Division of Animal House, Faculty of Science, Prince of Songkla University, Thailand. All animal procedures were reviewed and approved by the Animal Ethics Committee, Walailak
University (Protocol number: 004/2012) and were conducted according to the Guide for the Care and Use of Laboratory Animals, National Research Council. Rats were maintained in stainless-steel cages under constant conditions of temperature $\left(23 \pm 2^{\circ} \mathrm{C}\right)$, relative humidity (50$60 \%$ ) and lighting (12 h light/dark cycles). Animals were provided with a standard commercial rat diet and distilled water. Animals were acclimatized and closely monitored under laboratory conditions for 2 weeks before the commencement of the experiment.

\section{Experimental design and specimen collection}

Wistar rats were divided into five groups (5 rats per group). Saline group, rats were treated with a single intraperitoneal (i.p.) injection of $1 \mathrm{ml}$ of normal saline. Cis group, rats were injected with a single dose of cisplatin (20 $\mathrm{mg} / \mathrm{kg}$ b.w.) via i.p. route. Cis $+\alpha$-tocopherol group, rats were treated with a single dose of $\alpha$-tocopherol (250 $\mathrm{mg} / \mathrm{kg}$ b.w.); Cis + Cur group, rats were treated with a single dose of curcumin (200 $\mathrm{mg} / \mathrm{kg}$ b.w.); and Cis $+\alpha-$ tocopherol + Cur group, rats were treated with a single dose of combined $\alpha$-tocopherol $(250 \mathrm{mg} / \mathrm{kg}$ b.w.) and curcumin $(200 \mathrm{mg} / \mathrm{kg}$ b.w.), via i.p. route for $24 \mathrm{~h}$ prior a single dose injection of cisplatin (20 mg/kg b.w.) [16]. Following $72 \mathrm{~h}$ of first injection, rats were anesthetized with thiopental sodium intraperitoneally $(50 \mathrm{mg} / \mathrm{kg}$ b.w.). The peripheral blood from heart was collected in clot activator tubes. Then, rats were euthanized by anesthetizing thiopental sodium overdose $(100 \mathrm{mg} / \mathrm{kg}$ b.w.). After opening the abdominal cavity, the liver was harvested and immediately washed in ice-cold isotonic saline.

\section{Determination of serum AST and ALT levels}

Blood samples were centrifuged at $3000 \mathrm{rpm}$ for $5 \mathrm{~min}$. Sera were collected and the levels of serum ALT and AST were measured using a Cobas Mira Plus CC Chemistry Analyzer (Switzerland).

\section{Determination of liver MDA levels}

The liver tissue was homogenized to give a final concentration of $50 \mathrm{mg} / \mathrm{mL}$ in phosphate buffered saline (PBS) containing $1 \mathrm{X}$ butylated hydroxytoluene (BHT), homogenized on ice and centrifuged at $10000 \times \mathrm{g}$ for $5 \mathrm{~min}$ to collect supernatant. In accordance with the protocol of an OxiSelect ${ }^{\mathrm{TM}}$ TBARS Assay Kit (Cell Biolabs, Cat No.: STA-330, San Diego, CA, USA), $100 \mu \mathrm{L}$ of samples or MDA standard was added to separate microcentrifuge tubes, and then $100 \mu \mathrm{L}$ of the SDS lysis solution was added and mixed thoroughly. The samples were then incubated for $5 \mathrm{~min}$ at room temperature, $250 \mu \mathrm{L}$ of thiobarbituric acid (TBA) reagent was added, and then each tube was closed and incubated at $95^{\circ} \mathrm{C}$ for $60 \mathrm{~min}$. The tubes were then removed and cooled to room temperature in an ice bath for $5 \mathrm{~min}$. All sample tubes were then 
centrifuged at $3000 \mathrm{rpm}$ for $15 \mathrm{~min}$, the supernatant was removed from the samples, and then finally $200 \mu \mathrm{L}$ of samples and MDA standard was transferred to a 96-well microplate compatible with a spectrophotometric plate reader. The absorbance was read at $532 \mathrm{~nm}$.

\section{Determination of liver SOD activity}

The liver tissue was homogenized to give a final concentration of $50 \mathrm{mg} / \mathrm{ml}$ in cold $1 \mathrm{X}$ lysis buffer (containing $10 \mathrm{mM}$ Tris, $\mathrm{pH} 7.5,150 \mathrm{mM} \mathrm{NaCl}$ and $0.1 \mathrm{mM}$ EDTA), centrifuged at $12000 \times \mathrm{g}$ for $10 \mathrm{~min}$ and the supernatant was collected for analysis. In accordance with the protocol of an OxiSelect ${ }^{\text {TM }}$ SOD Activity Assay Kit (Cell Biolabs, Cat No.: STA-340, San Diego, CA, USA), $20 \mu \mathrm{L}$ of samples, $5 \mu \mathrm{L}$ of xanthine solution, $5 \mu \mathrm{L}$ of chromagen solution, $5 \mu \mathrm{L}$ of $10 \mathrm{X}$ SOD assay buffer and $50 \mu \mathrm{L}$ of deionized water were added (total volume of $90 \mu \mathrm{L}$ ) to a 96-well microplate, and then $10 \mu \mathrm{L}$ of pre-diluted $1 \mathrm{X}$ xanthine oxidase solution was added to each well. The samples were then mixed well and incubated for $1 \mathrm{~h}$ at $37^{\circ} \mathrm{C}$. The absorbance was read using the spectrophotometric microplate reader at $490 \mathrm{~nm}$.

\section{Determination of liver catalase activity}

The liver tissue was homogenized to give a final concentration of $50 \mathrm{mg} / \mathrm{ml}$ in cold PBS with $1 \mathrm{mM}$ EDTA, centrifuged at $10000 \times \mathrm{g}$ for $15 \mathrm{~min}$ at $4^{\circ} \mathrm{C}$ and the supernatant was collected. In accordance with the protocol of an OxiSelect ${ }^{\mathrm{TM}}$ Catalase Activity Assay Kit (Cell Biolabs, Cat No: STA-341, San Diego, CA, USA), $20 \mu \mathrm{l}$ of the diluted catalase standard or sample and $50 \mu \mathrm{l}$ of the $\mathrm{H}_{2} \mathrm{O}_{2}$ working solution $(12 \mathrm{mM})$ were added to a 96 well microplate. The samples were then mixed well and incubated for $1 \mathrm{~min}$. The reaction was stopped by adding $50 \mu \mathrm{l}$ of the catalase quencher into each well and mixed thoroughly, $5 \mu \mathrm{l}$ of each reaction well was transferred to a fresh well, $250 \mu \mathrm{l}$ of the chromogenic working solution was added to each well. The samples were then mixed well and incubated for $60 \mathrm{~min}$. The absorbance was read using the spectrophotometric microplate reader at $520 \mathrm{~nm}$.

\section{Protein determination}

Protein content was estimated by Bradford assay (Sigma, USA) using bovine serum albumin (BSA) as standard.

\section{Liver histology}

The liver tissue was preserved in 10\% neutral buffered formalin solution for $24 \mathrm{~h}$ and washed with $70 \%$ ethanol. Tissue was then placed in small metal caskets, stirred by a magnetic stirrer, dehydrated using alcohol series from $70 \%$ to $100 \%$ alcohol and embedded in paraffin using an embedding machine. Paraffin block was sectioned using a rotary ultra-microtome, distributed onto glass slides and then dried overnight. Slide was observed under a light microscope after being stained with hematoxylin and eosin (H\&E) dyes and mounted.

\section{Liver NADPH oxidase gene expression by reverse transcription-polymerase chain reaction (RT-PCR)}

Total RNA was extracted from the liver tissue by RNeasy mini kit. RNA content and purity were measured by a UV spectrophotometer. RT-PCR was done using the extracted RNA for detection of NADPH oxidase gene. For amplification of the targets gene, reverse transcription and PCR were run in two separate steps. Briefly, Reaction mixture of RT reaction containing $1 \mu \mathrm{g}$ total RNA, $0.5 \mu \mathrm{g}$ random primer, $5 \times \mathrm{RT}$ buffer, 2.5 $\mathrm{mmol} / \mathrm{l} \mathrm{dNTP}, 20 \mathrm{U}$ RNase inhibitor and $200 \mathrm{U}$ MMLV reverse transcriptase in a total volume of $25 \mu \mathrm{l}$ was incubated at $37^{\circ} \mathrm{C}$ for $60 \mathrm{~min}$, then heated to $95^{\circ} \mathrm{C}$ for $5 \mathrm{~min}$ to inactivate MMLV. PCR was carried out with $1.5 \mu \mathrm{l}$
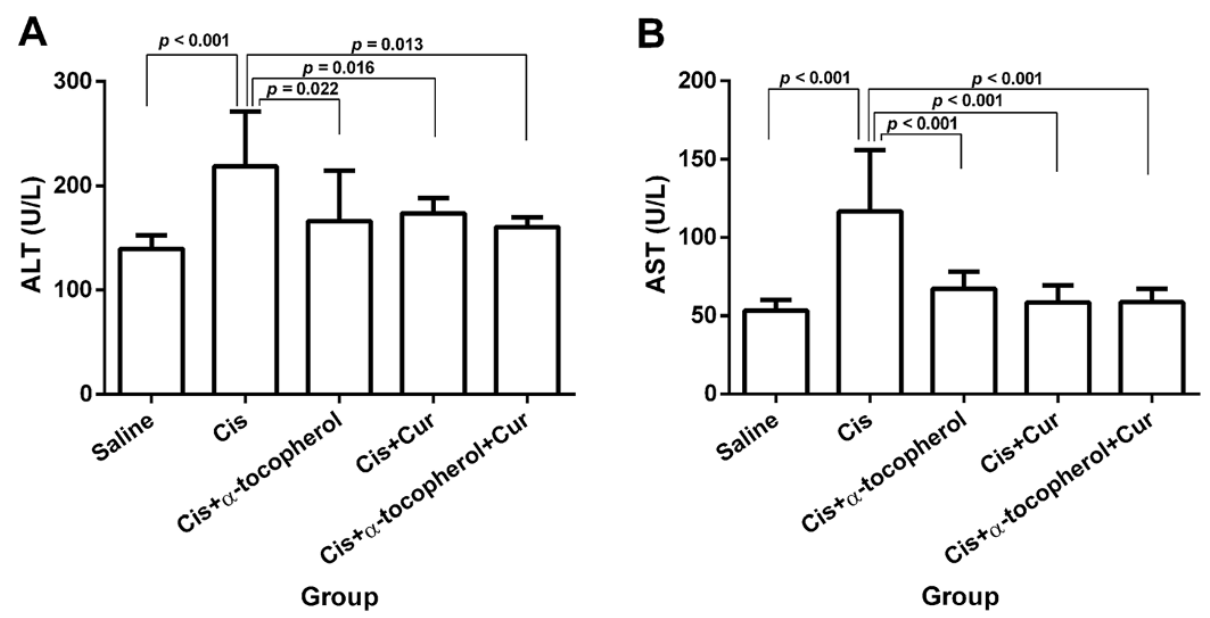

Figure 1 Serum AST levels (A) and serum ALT levels (B). Values represent the mean \pm S.E.M. ( $n=5)$. Cis: cisplatin, Cur: curcumin. 


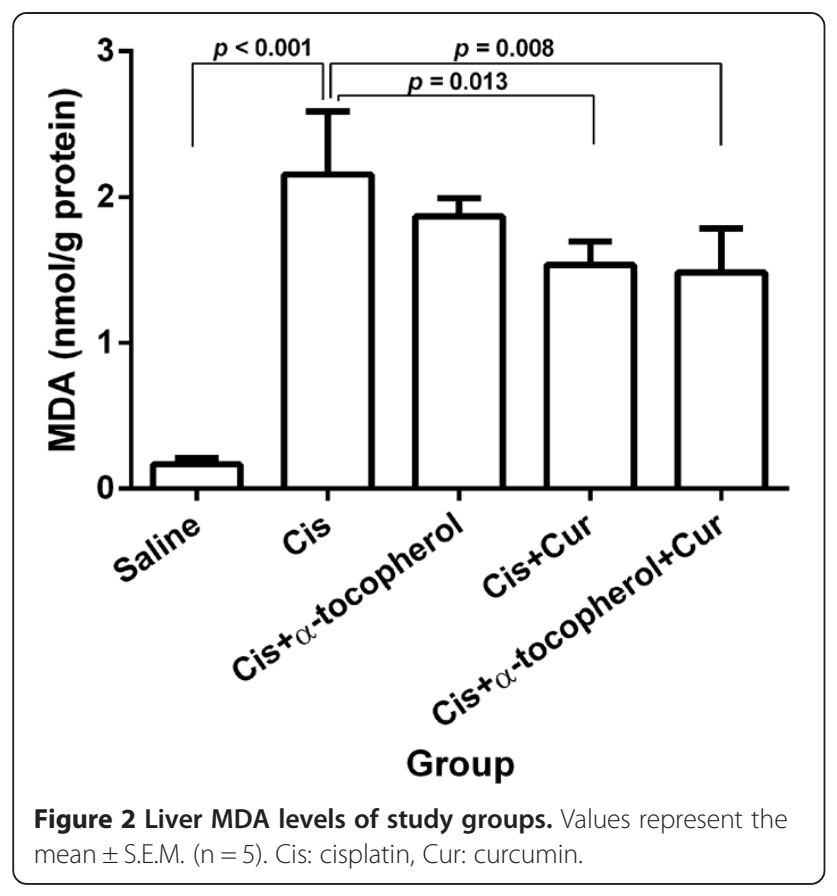

RT products, $10 \times \mathrm{PCR}$ buffer (without $\mathrm{Mg}^{2+}$ ) $2.5 \mu \mathrm{l}, 2.0$ $\mu \mathrm{l}$ dNTP $(2.5 \mathrm{mmol} / \mathrm{l}), 2.0 \mu \mathrm{l} \mathrm{MgCl}_{2}(25 \mathrm{mmol} / \mathrm{l}), 0.5 \mu \mathrm{l}$ each primer $(20 \mu \mathrm{mol} / \mathrm{l})$ of $\beta$-actin, $0.5 \mu \mathrm{l}$ each primer of gene to be tested $(20 \mu \mathrm{mol} / \mathrm{l})$ and $1 \mathrm{U}$ of Taq DNA polymerase, in a final volume of $25 \mu \mathrm{l}$. Thermal cycler conditions were as follows: a first denaturing cycle at $97^{\circ} \mathrm{C}$ for $5 \mathrm{~min}$, followed by a variable number of cycles of amplification defined by denaturation at $96^{\circ} \mathrm{C}$ for $1.5 \mathrm{~min}$, annealing for $1.5 \mathrm{~min}$ and extension at $72^{\circ} \mathrm{C}$ for $3 \mathrm{~min}$. A final extension cycle of $72^{\circ} \mathrm{C}$ for 15 min was included [17]. The primers including:

NADPH oxidase: Forward primer: 5'-GGAAATAGAA AGTTGACTGGCCC -3'
Reverse primer: 5'-GTATGAGTGCCATCCAGAGCAG-3'

Beta actin: Forward primer: 5'TGTTGTCCCTGTAT GCCTCT-3'

Reverse primer: 5'-TAATGTCACGCACGATTTCC-3'

The sample was equally loaded on $2 \%$ gel agarose, stained with ethidium bromide and visualized by UV transilluminator. The amount of PCR product was quantified using the gel and image analysis software (Syngene, USA).

\section{Statistical analysis}

Results were expressed as mean \pm standard error of the mean (S.E.M.). Differences between groups were determined by one-way analysis of variance (ANOVA). Post hoc testing was performed for group comparisons using the Least Significant Difference (LSD) test and $p<0.05$ was considered significant.

\section{Results}

\section{Effect of the treatment on liver enzymes}

Cisplatin elicited a significant increase of the serum AST and ALT levels compared to the control (saline) group $(p<0.001)$ (Figures 1A and B). Curcumin and/or $\alpha$ tocopherol significantly demonstrated the reduction of serum AST levels $(p<0.001)$ (Figure 1A). The alphatocopherol group, curcumin group and combined curcumin with $\alpha$-tocopherol group also significantly elicited the reduction of the serum ALT levels compared to the cisplatin-treated group $(p=0.022, p=0.016$ and $p=$ 0.013 , respectively) (Figure 1B).

\section{Effect of the treatment on lipid peroxidation}

Cisplatin demonstrated a marked increase of hepatic MDA levels compared to the saline group $(p<0.001)$ indicating the enhancement of lipid peroxidation (Figure 2). The cisplatin pre-treated with curcumin group and
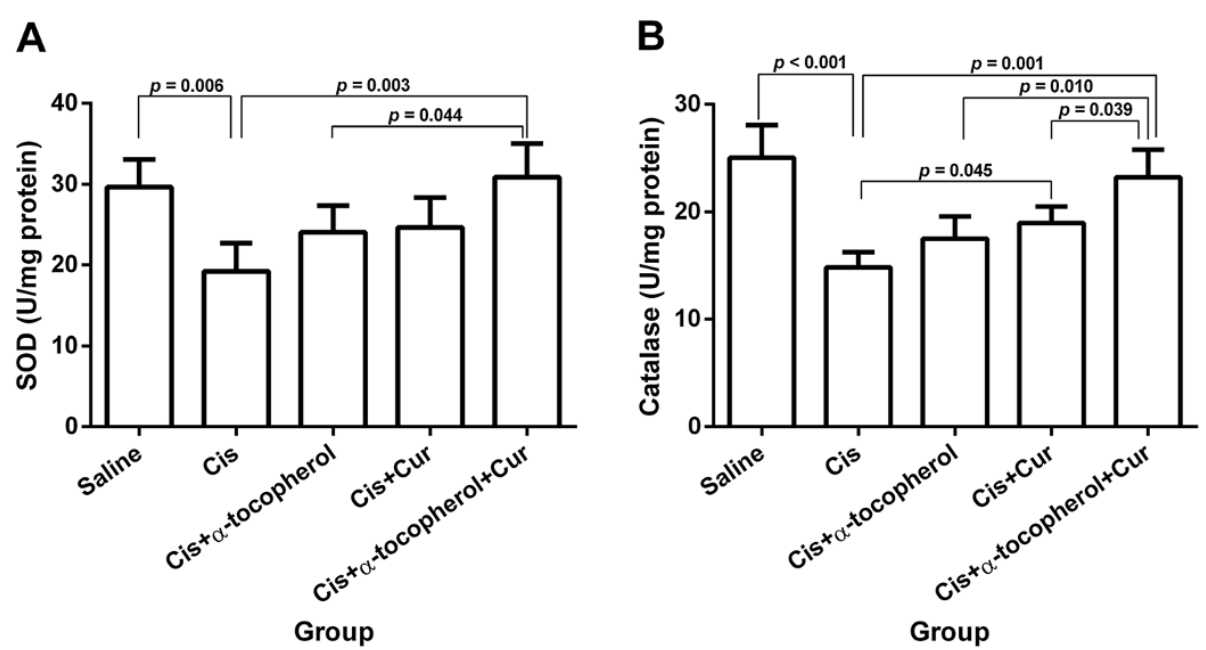

Figure 3 Enzymatic antioxidant activities of study groups: (A) SOD activity and (B) catalase activity. Values represent the mean \pm S.E.M. $(n=5)$. Cis: cisplatin, Cur: curcumin. 


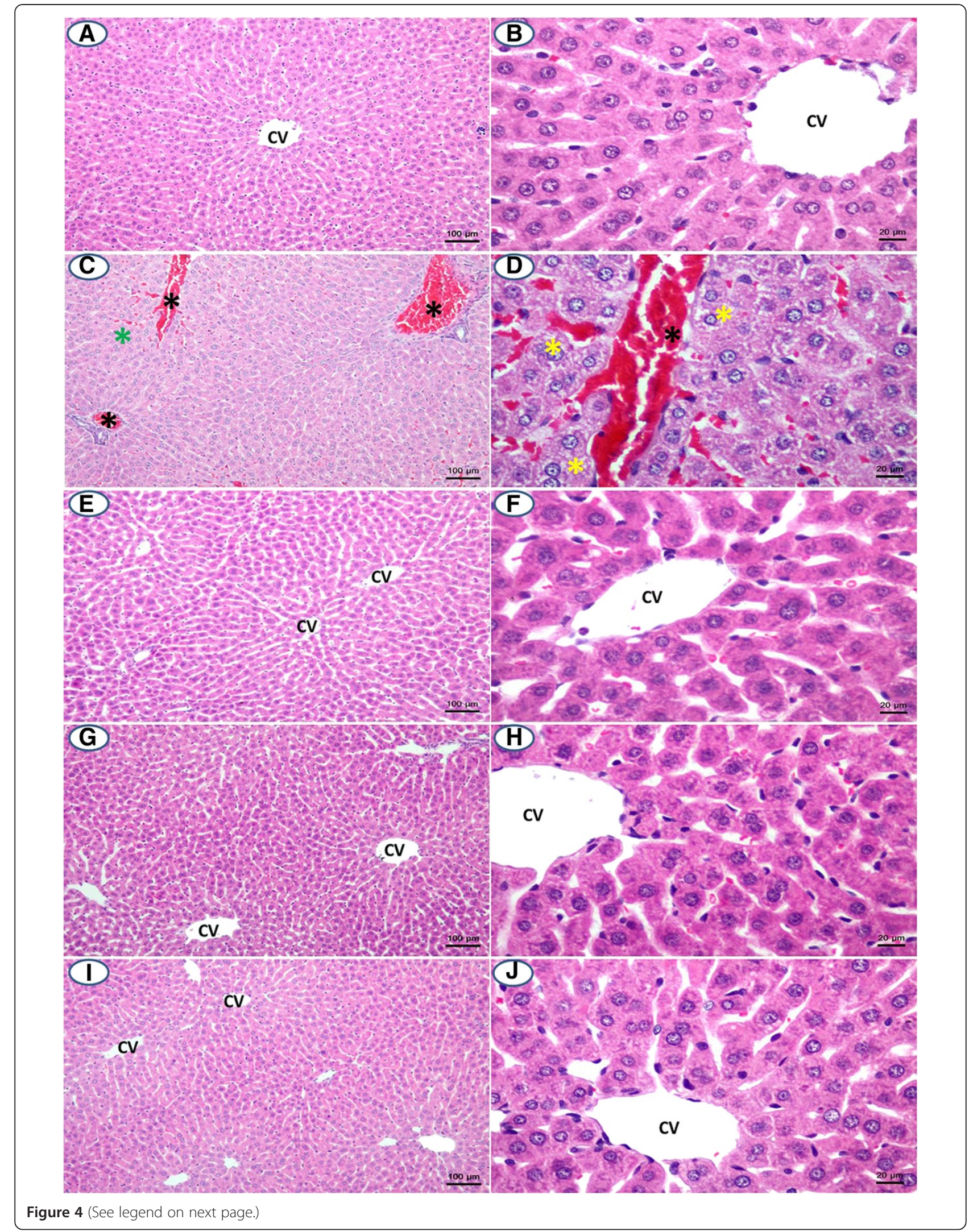


(See figure on previous page.)

Figure 4 Liver histology of study groups (H\&E staining): (A, B) control group, (C, D) cisplatin-treated group, (E, F) cisplatin pre-treated with a-tocopherol group, $(\mathrm{G}, \mathrm{H})$ cisplatin pre-treated with curcumin group and $(\mathrm{I}, \mathrm{J})$ cisplatin pre-treated with combined curcumin and a-tocopherol group. The black asterisk indicates congestion. The green asterisk indicates disorganization of hepatic cords. The yellow asterisk indicates ground glass appearance of hepatocytes. Scale bar $=100$ and $20 \mu \mathrm{m}$, respectively. $\mathrm{CV}=$ central vein.

combined curcumin and $\alpha$-tocopherol group revealed a significant reduce MDA levels compared to the cisplatintreated group ( $p=0.013$ and $p=0.008$, respectively).

\section{Effect of the treatment on enzymatic antioxidant activities}

As shown in Figures $2 \mathrm{~A}$ and $3 \mathrm{~B}$, cisplatin significantly led to the reduction of $\operatorname{SOD}(p=0.006)$ and calalase activities $(p<0.001)$ compared to the saline group. The cisplatin pre-treated with combined curcumin and $\alpha$ tocopherol group significantly elicited the increased SOD activity compared to the cisplatin-treated group $(p=0.003)$ and cisplatin pre-treated with $\alpha$-tocopherol group $(p=0.044)$ (Figure 3A). The cisplatin pre-treated with curcumin group showed the significant increase of catalase activity compared to the cisplatin-treated group $(p=0.045)$. Moreover, the cisplatin pre-treated with combined curcumin and $\alpha$-tocopherol group significantly elicited the increase of catalase activity compared to the cisplatin-treated group $(p=0.001)$, cisplatin pretreated with $\alpha$-tocopherol group $(p=0.010)$ and cisplatin pre-treated with curcumin group $(p=0.039)$ (Figure $3 \mathrm{~B})$.

\section{Effect of the treatment on liver histology}

Cisplatin at $20 \mathrm{mg} / \mathrm{kg}$ b.w. caused liver congestion, disorganization of hepatic cords and ground glass appearance of hepatocytes (Figures $4 \mathrm{C}$ and D). Pretreatment with curcumin and/or $\alpha$-tocopherol was able to improve liver pathology induced by cisplatin at 20 $\mathrm{mg} / \mathrm{kg}$ b.w. (Figures 4E-J).
Effect of the treatment on liver NADPH oxidase gene expression As shown in Figures $5 \mathrm{~A}$ and $\mathrm{B}$, treatment with cisplatin revealed a significant increase of mRNA levels of NADPH oxidase compared to the saline group $(p=0.001)$. The cisplatin pre-treated with combined curcumin and $\alpha$ tocopherol-treated groups significantly showed the reduction of mRNA levels of NADPH oxidase compared to the cisplatin-treated group $(p=0.039)$.

\section{Discussion}

In the study, hepatotoxicity induced by cisplatin was recognized by the alterations of the biochemical, histological and molecular parameters. Biochemical alterations included the increase of liver enzyme levels including AST and ALT, the increase of MDA levels and the decrease of SOD and catalase activities. MDA is one of the most potential biomarkers of lipid peroxidation [18]. Histological changes comprised of liver congestion, disorganization of hepatic cords and ground glass appearance of hepatocytes. The molecular alteration indicates the up-regulation of $\mathrm{NADPH}$ oxidase gene expression. From this study, we suggest that up-regulation of NADPH oxidase gene expression may be caused the enhancement of ROS production by increasing $\mathrm{O}_{2}{ }^{--}$production, ultimately resulting in generation of lipid peroxidation. Lipid peroxidation is demonstrated to induce disturbance of membrane function and integrity [19]. Moreover, the reduced activities of enzymatic antioxidants led to the decreased scavenging activities against ROS, eventually causing oxidative stress.
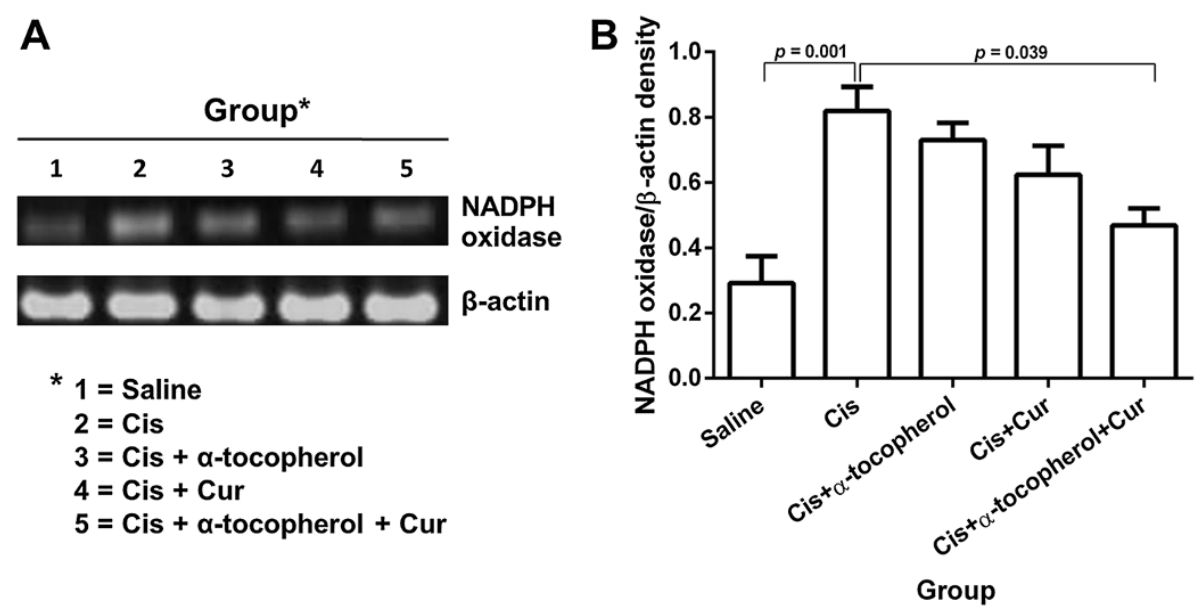

Figure $\mathbf{5}$ Liver NADPH oxidase gene expressions in study groups. (A) agarose gel electrophoresis showing gene expression of NADPH oxidase by RT-PCR and (B) density of NADPH oxidase gene compared with $\beta$-actin. Values represent the mean \pm S.E.M. ( $n=5$ ). Cis: cisplatin, Cur: curcumin. 
Reduction of antioxidant defense system was concerned in various pathological conditions induced by oxidative stress. The study indicates that oxidative stress has been implicated in the pathogenesis of cisplatin-induced hepatotoxicity. Many studies have focused on the alternative approach to protect cisplatin-induced hepatotoxicity using natural products-derived antioxidants [2,20,21]. Our work is the first report to demonstrate the combination of curcumin and $\alpha$-tocopherol for prevention of cisplatininduced hepatotoxicity.

Curcumin [1,7-bis(4-hydroxy-3-methoxyphenyl)-1,6-heptadiene-3,5-dione] is a natural phenolic compound from turmeric which has demonstrated a variety of pharmacological effects such as antioxidant against hexavalent chromium $[\mathrm{Cr}(\mathrm{VI})]$ compound-induced renal oxidant damage, anti-inflammation against neurodegenerative, cardiovascular, pulmonary, metabolic, autoimmune and neoplastic diseases, anti-cancer and enhanced wound healing [22-24]. Curcumin has been reported as the powerful antioxidant in different in vitro assays. H-atom donation from phenolic group of curcumin was believed to responsible for the superb antioxidant properties [25]. Moreover, the phenolic compound of curcumin has been confirmed to play the key role in the antioxidant activity [26]. Additionally, curcumin exhibited the highest antioxidant capacity compared to turmeric's other two curcuminoids including demethoxycurcumin and bisdemethoxycurcumin [27]. This study revealed that pre-treatment with curcumin alone was able to normalize the levels of liver enzymes and lipid peroxidation biomarker, the activity of catalase and liver histopathology in cisplatin-treated rats. The activities of curcumin were similar to previous reports $[28,29]$.

Alpha-tocopherol is an isoform of lipid-soluble vitamin E which acts as a powerful antioxidant [30,31]. The pretreatment with combined curcumin and $\alpha$-tocopherol led to the improvement of the liver enzymes levels and lipid peroxidation biomarker, the activities of enzymatic antioxidants, liver histopathology and gene expression of liver NADPH oxidase in cisplatin-treated rats. Previous reports also showed the augmented activity of combined curcumin with other antioxidant compound. Combination of ascorbic acid with curcumin increases the antioxidant activity [32]. Co-administration of vitamin $\mathrm{E}$ and curcumin improved the activities of enzymatic antioxidant including cytosolic catalase, cytosolic glutathione peroxidase-1 (GPx1), mitochondrial SOD2 and glutathione reductase, and normalized GPx1 protein expression in 1-thyroxine-induced hyperthyroidism in rat [33]. From the results, we suggested that NADPH oxidase play the key role in oxidative stress state induced by cisplatin. Previous studies indicated that NADPH oxidase is the main enzymatic source of ROS production which is responsible for oxidative stress in various diseases via the underlying mechanisms of NADPH oxidase activation [34,35]. This study demonstrated the potent antioxidant property of combined curcumin and $\alpha-$ tocopherol to reduce oxidative damages of liver induced by cisplatin. However, the exact mechanism is still unknown. The down-regulations of NADPH oxidase gene expression may be involved in the abrogation of oxidative stress via reduction of reactive oxygen species (ROS) generation.

\section{Conclusions}

We suggest that oxidative stress has been implicated in the pathogenesis of cisplatin-induced hepatotoxicity by enhancing ROS generation through up-regulation of NADPH oxidase gene and by reducing activities of enzymatic antioxidants. These findings indicate that pretreatment with combined curcumin and $\alpha$-tocopherol can protect cisplatin-induced hepatotoxicity including biochemical, histological and molecular aspects. The study provides the evidence of combined curcumin and $\alpha$-tocopherol as the new adjuvant of cisplatin to abrogate the hepatotoxicity upon cancer chemotherapy.

\section{Abbreviations}

ALT: Alanine aminotransferase; ANOVA: Analysis of variance, AST, Aspartate aminotransferase; b.w: Body weight; BHT: Butylated hydroxytoluene; BSA: Bovine serum albumin; Cisplatin: cis-Diammineplatinum (II) dichloride; $\operatorname{Cr}(\mathrm{VI})$ : hexavalent chromium; DNA: Deoxyribonucleic acid; EDTA: Ethylenediaminetetraacetic acid; GPx: Glutathione peroxidase; H\&E: Hematoxylin and eosin; $\mathrm{H}_{2} \mathrm{O}_{2}$ : Hydrogen peroxide; i.p: Intraperitoneal; LSD: Least significant difference; MDA: Malondialdehyde; $\mathrm{MgCl}_{2}$ : Magnesium chloride; NaCl: Sodium chloride; NADPH oxidase: Nicotinamide adenine dinucleotide phosphate oxidase; $\mathrm{O}_{2}$ : Superoxide radical; $\mathrm{OH}$ : Hydroxyl radical; PBS: Phosphate buffered saline; RNA: Ribonucleic acid; ROS: Reactive oxygen species; RT-PCR: Reverse transcription-polymerase chain reaction; S.E.M:: Standard error of the mean; SDS: Sodium dodecyl sulfate; SOD: Superoxide dismutase; TBA: Thiobarbituric acid; TBARS: Thiobarbituric acid reactive substances.

\section{Competing interests}

The authors declare that they have no competing interests.

\section{Authors' contributions}

SP conceived this study, and designed the experiments and performed most of the experiments. CP contributed to the liver histology analysis. PK carried out the liver SOD and catalase analysis. All authors analyzed the data, and discussed and concluded the results. SP and PS provided final editing to the manuscript. All authors read and approved the final manuscript.

\section{Acknowledgements}

This research was supported by a grant from the Institute of Research and Development (under the contract WU 55307), Walailak University, Thailand. We are thankful to Miss Dararat Punwong, Medical Technologist from School of Allied Health Sciences and Public Health, Walailak University for laboratory assistant and also thank the Dean and all staff of School of Medicine, Walailak University for their kind support.

\section{Author details}

${ }^{1}$ School of Medicine, Walailak University, Nakhon Si Thammarat 80161, Thailand. ${ }^{2}$ Department of Pathobiology, Faculty of Science, Mahidol University, Bangkok 10400, Thailand.

Received: 12 November 2013 Accepted: 24 March 2014

Published: 28 March 2014

\section{References}

1. Rabik CA, Dolan ME: Molecular mechanisms of resistance and toxicity associated with platinating agents. Cancer Treat Rev 2007, 33:9-23.

2. Liao $Y, L U X, L U C, L i G$, Jin $Y$, Tang H: Selection of agents for prevention of cisplatin-induced hepatotoxicity. Pharmacol Res 2008, 57(2):125-131. 
3. Palipoch S, Punsawad C: Biochemical and histological study of rat liver and kidney injury induced by Cisplatin. J Toxicol Pathol 2013, 26(3):293-299.

4. Arany I, Safirstein RL: Cisplatin nephrotoxicity. Semin Nephrol 2003, 23:460-464.

5. Robbins MEC, Zhao W, Davis CS, Toyokuni S, Bonsib SM: Radiation-induced kidney injury: a role for chronic oxidative stress? Micron 2002, 33(2):133-141.

6. MacNee W: Oxidative stress and lung inflammation in airways disease. Eur J Pharmacol 2001, 429(1-3):195-207.

7. Palipoch S: A review of oxidative stress in acute kidney injury: protective role of medicinal plants-derived antioxidants. Afr J Tradit Complement Altern Med 2013, 10:88-93.

8. Babior BM: NADPH oxidase. Curr Opin Immunol 2004, 16:42-47.

9. Pan X, Dai Y, Li X, Niu N, Li W, Liu F, Zhao Y, Yu Z: Inhibition of arsenic induced-rat liver injury by grape seed exact through suppression of NADPH oxidase and TGF- $\beta$ /Smad activation. Toxicol Appl Pharmacol 2011, 254(3):323-331.

10. Fujimori $\mathrm{N}$, Oono $\mathrm{T}$, Igarashi $\mathrm{H}$, Ito $\mathrm{T}$, Nakamura $\mathrm{T}$, Uchida $\mathrm{M}, \mathrm{Coy} \mathrm{DH}$, Jensen RT, Takayanagi R: Vasoactive intestinal peptide reduces oxidative stress in pancreatic acinar cells through the inhibition of NADPH oxidase. Peptides 2011, 32(10):2067-2076.

11. Muller FL, Song W, Liu Y, Chaudhuri A, Pieke-Dahl S, Strong R, Huang T-T, Epstein CJ, Roberts LJ 2nd, Csete M, Faulkner JA, Van Remmen H: Absence of CuZn superoxide dismutase leads to elevated oxidative stress and acceleration of age-dependent skeletal muscle atrophy. Free Radic Biol Med 2006, 40(11):1993-2004.

12. Kessova IG, Ho Y-S, Thung S, Cederbaum Al: Alcohol-induced liver injury in mice lacking Cu, Zn-superoxide dismutase. Hepatology 2003, 38(5):1136-1145.

13. Kim SJ, Lee JW, Jung YS, Kwon DY, Park HK, Ryu CS, Kim SK, Oh GT, Kim YC: Ethanol-induced liver injury and changes in sulfur amino acid metabolomics in glutathione peroxidase and catalase double knockout mice. J Hepatol 2009, 50(6):1184-1191.

14. M. Khopde S, Priyadarsini KI, Venkatesan P, Rao MNA: Free radical scavenging ability and antioxidant efficiency of curcumin and its substituted analogue. Biophys Chem 1999, 80(2):85-91.

15. Gao S, Duan X, Wang X, Dong D, Liu D, Li X, Sun G, Li B: Curcumin attenuates arsenic-induced hepatic injuries and oxidative stress in experimental mice through activation of Nrf2 pathway, promotion of arsenic methylation and urinary excretion. Food Chem Toxicol 2013, 59:739-747.

16. Palipoch S, Punsawad C, Chinnapun C, Suwannalert P: Amelioration of cisplatin-induced nephrotoxicity in rats by curcumin and a-tocopherol. Trop J Pharm Res 2013, 12(6):973-979.

17. Rashed LA, Hashem RM, Soliman HM: Oxytocin inhibits NADPH oxidase and P38 MAPK in cisplatin-induced nephrotoxicity. Biomed Pharmacother 2011, 65:474-480.

18. Horton AA, Fairhurst S: Lipid peroxidation and mechanisms of toxicity. Crit Rev Toxicol 1987, 18(1):27-79.

19. Etsuo N: Lipid peroxidation: Physiological levels and dual biological effects. Free Radic Biol Med 2009, 47(5):469-484.

20. Kart A, Cigremis $Y$, Karaman M, Ozen H: Caffeic acid phenethyl ester (CAPE) ameliorates cisplatin-induced hepatotoxicity in rabbit. Exp Toxicol Pathol 2010, 62(1):45-52.

21. Hassan I, Chibber S, Naseem I: Ameliorative effect of riboflavin on the cisplatin induced nephrotoxicity and hepatotoxicity under photoillumination. Food Chem Toxicol 2010, 48(8-9):2052-2058

22. Molina-Jijón E, Tapia E, Zazueta C, El Hafidi M, Zatarain-Barrón ZL, HernándezPando R, Medina-Campos ON, Zarco-Márquez G, Torres I, Pedraza-Chaverri J: Curcumin prevents $\mathrm{Cr}(\mathrm{VI})$-induced renal oxidant damage by a mitochondrial pathway. Free Radic Biol Med 2011, 51(8):1543-1557.

23. Aggarwal BB, Harikumar KB: Potential therapeutic effects of curcumin, the anti-inflammatory agent, against neurodegenerative, cardiovascular, pulmonary, metabolic, autoimmune and neoplastic diseases. Int I Biochem Cell Biol 2009, 41(1):40-59.

24. Maheshwari RK, Singh AK, Gaddipati J, Srimal RC: Multiple biological activities of curcumin: a short review. Life Sci 2006, 78(18):2081-2087.

25. Ak T, Gülçin I: Antioxidant and radical scavenging properties of curcumin. Chem Biol Interact 2008, 174(1):27-37.

26. Galano A, Álvarez-Diduk R, Ramírez-Silva MT, Alarcón-Ángeles G, Rojas-Hernández A: Role of the reacting free radicals on the antioxidant mechanism of curcumin. Chem Phys 2009, 363(1-3):13-23.

27. Jayaprakasha GK, Jaganmohan Rao L, Sakariah KK: Antioxidant activities of curcumin, demethoxycurcumin and bisdemethoxycurcumin. Food Chem 2006, 98(4):720-724.
28. Naik SR, Thakare VN, Patil SR: Protective effect of curcumin on experimentally induced inflammation, hepatotoxicity and cardiotoxicity in rats: Evidence of its antioxidant property. Exp Toxicol Pathol 2011, 63(5):419-431.

29. Eybl V, Kotyzova D, Koutensky J: Comparative study of natural antioxidants curcumin, resveratrol and melatonin - in cadmium-induced oxidative damage in mice. Toxicology 2006, 225(2-3):150-156.

30. Banudevi S, Krishnamoorthy G, Venkataraman P, Vignesh C, Aruldhas MM, Arunakaran J: Role of a-tocopherol on antioxidant status in liver, lung and kidney of PCB exposed male albino rats. Food Chem Toxicol 2006, 44(12):2040-2046.

31. Sodhi S, Sharma A, Brar APS, Brar RS: Effect of a tocopherol and selenium on antioxidant status, lipid peroxidation and hepatopathy induced by malathion in chicks. Pestic Biochem Phys 2008, 90(2):82-86.

32. Khalil OAK, de Faria Oliveira OMM, Vellosa JCR, de Quadros AU, Dalposso LM, Karam TK, Mainardes RM, Khalil NM: Curcumin antifungal and antioxidant activities are increased in the presence of ascorbic acid. Food Chem 2012, 133(3):1001-1005.

33. Subudhi U, Chainy GBN: Expression of hepatic antioxidant genes in I-thyroxine-induced hyperthyroid rats: Regulation by vitamin $\mathrm{E}$ and curcumin. Chem Biol Interact 2010, 183(2):304-316.

34. Huang X, Sun M, Li D, Liu J, Guo H, Dong Y, Jiang L, Pan Q, Man Y, Wang S, Li J: Augmented NADPH oxidase activity and p22phox expression in monocytes underlie oxidative stress of patients with type 2 diabetes mellitus. Diabetes Res Clin Pract 2011, 91(3):371-380.

35. Qin F, Simeone M, Patel R: Inhibition of NADPH oxidase reduces myocardial oxidative stress and apoptosis and improves cardiac function in heart failure after myocardial infarction. Free Radic Biol Med 2007, 43(2):271-281.

doi:10.1186/1472-6882-14-111

Cite this article as: Palipoch et al:: Hepatoprotective effect of curcumin and alpha-tocopherol against cisplatin-induced oxidative stress. BMC Complementary and Alternative Medicine 2014 14:111.

\section{Submit your next manuscript to BioMed Central and take full advantage of:}

- Convenient online submission

- Thorough peer review

- No space constraints or color figure charges

- Immediate publication on acceptance

- Inclusion in PubMed, CAS, Scopus and Google Scholar

- Research which is freely available for redistribution 